\title{
Диктатура пролетариата - это форма насилия, революция - это форма насилия: 100 лет русской революции 1917 года. \\ Интервью с профессором Юрием Слёзкиным, Калифорнийский университет в Беркли
}

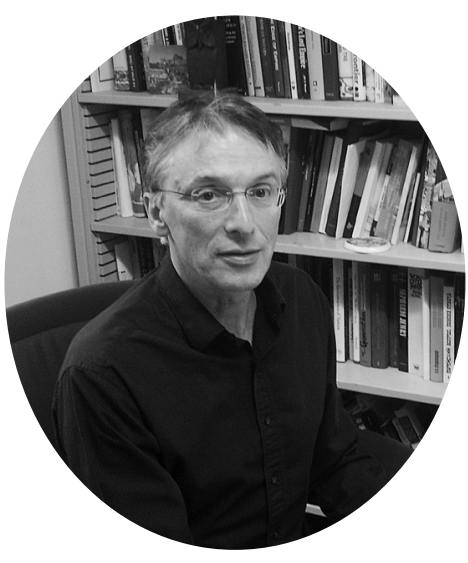

ЮРИЙ САЁЗКИН профессор истории и Аиректор программы евразийских и восточно-европейских исследований в Калифорнийском университете в Беркли. Окончил Московский государственный университет в 1978 году и получил Аокторскую степень в Университете штата Техас в Остине в 1989 году. В 2008 году он был избран чиеном Американской академии искусств и наук.

Что вы можете сказать, после 100 лет, о памлти русских революций, февральской и октлбрьской?

Я думаю, что это зависит от того, с какой точки зрения на это смотреть.

С точки зрения истории. Я обращаюсь к вам как к историку, который занимается непосредственно этим периодом, который может представить его с разных точек зрения.

Ну, как я понимаю, повсюду - в вашем обществе, в российском обществе, в Америке, гАе я живу - без какого-то отношения к русской революции нельзя себе преАставить современную жизнь. И, конечно, в первую очередь, это захват власти большевиками, создание Советского государства и коммунистического режима в России. Наверное, главная часть этой памяти, главная составцяющая. Об этом можно говорить более конкретно.

\section{Что говорит русскал эмиграция в США о революции?}

Я не занимаюсь специально русской эмиграцией в Америке. У меня какие-то анекдотические эпизоды всплывают в памяти, но сам я этим не занимаюсь. Есть цюАи - историки, колмеги, - которые этим занимаются. И, конечно, на этот вопрос нельзя ответить однозначно, потому что в России принято говорить о трех волнах русской эмиграции в Америку. Первая волна - послереволюционная, в значительной степени состоящая

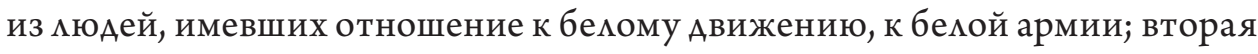




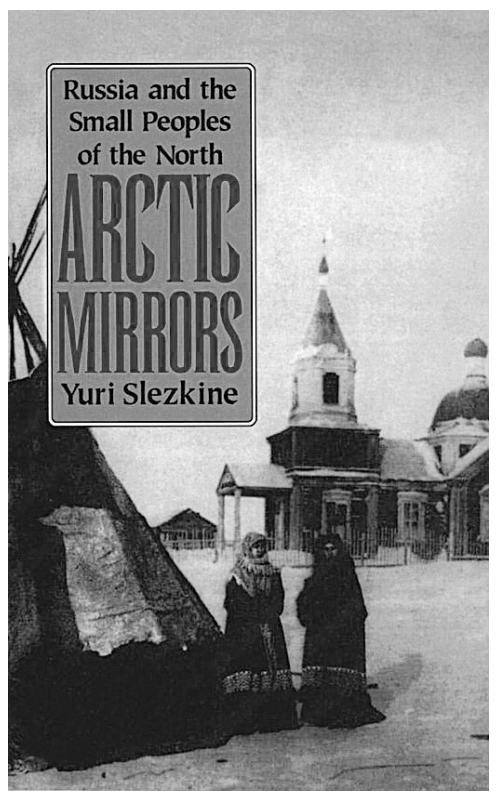

волна - послевоенная, которая быма менее заметна. И третья волна, по большей части еврейская. И наконец, нужно Аобавить к этой волне поменьше, эмигрантов из уже новой России - многие из них профессионалы, которые находят работу после распада Советского Союза, в рамках так называемой утечки мозгов.

Насколько архивь из Америки, Гувер способствовали изучению революиий?

В значитемьной степени. Гувер - самое кучшее, самое главное собрание по истории русской революции в Америке и, может быть, самое мучшее за пределами России. И это тем более важно, что в Америке история России, история русской революции, Советского Союза - это Аовоцьно крупная индустрия. Очень много профессионаков этим занимаются, поэтому важно то, к чему они имеют Аоступ, чем Аышат. В Советском Союзе некоторые архивы были неАоступны, в России ограничены. В Россию не все могут езАить. А зАесь есть, кроме Гувера, бахметьевский архив, Аругие.

Важно еще, что в послеАние гоАы Гувер купим в разных российских архивах очень хорошие материамы. Это, конечно, облегчает жизнь историков, которые тут базируются.

В Россию, в отличие от Германии и Франции, волна револющии приила с опозданием. Можем ми мы говорить об экспорте революции с запада на восток?

Экспорт, может быть, не самое кучшее слово. Конечно, большевики Аумами о себе, как о наслеАниках якобинцев, особенно первое покомение. Не могми шагу ступить, чтобы не подумать, что в этот момент ими на аналогичном этапе происходимо во Франции, и с чем это соотносится в истории французской революции. Конечно, не все читахи Маркса, но, поскомьку его тексты стали каноническим писанием, многие, так ими иначе, быми знакомы с революцией 1848 года, с Ауи Бонапартом, ощущали себя внутри канвы марксистского понимания истории, ощущахи себя частью вселенской истории. А в этой истории по марксистской схеме главной явцяется ревомюция, поэтому об экспорте можно говорить, но, мне кажется, в меньшей степени, чем о природе самой марксистской и бомь- 
шевистской идеологии, ее понимании хронологии, фимософии истории и кмючевой роли ревомюции в этой фимософии.

\section{Изначальная цель февральской револючии - это свержение царя и создание другого общества, другой жизни?}

Ну не знаю, наскомько можно говорить о том, что у феврацьской революции была цемь. Я не Аумаю, что можно говорить о цели в каком-то объективном смысле. У разных участников конфмикта быми разные цели. Но, конечно же, важная часть общества ожилала катакмизма. Очень многие называли это ревомюцией. Это связано с первой мировой войной, но не во всем, потомучто мечты о ревомюции, ощущение кризиса и неизбежности конца появимись горазАо раньше.

\section{В ием самал большая ошибка Керенского?}

Мне труано ответить. Есть мюАи, которые гораздо кучше знают эту историю, что и как происходило изо Аня в Аень. Наверное, можно сказать, что он не вполне отдавац себе отчет в симе большевиков и их организованности, цемеустремленности. И что его отношение к войне явцяется важной причиной его неуАачи, в том числе и в августе 1917 гоАа, во время «Корниловщины». Можно говорить о каких-то конкретных неправимьных решениях, можно говорить в целом о том, что, в отличие от большевиков, у него не бымо четко очерченной социамьной ими, вернее, политической базы.

Взаимосвязь между Питером и периферией: как волна революции повлияла на другие регионь?

Конечно, это очень важный вопрос. Вопрос, имеющий отношение к суаьбе гражАанской войны. Много копий сломано, слов потрачено, есть много объяснений, многие из них имеют право на существование, в том числе чисто тактические: что большевики, выиграв в Петрограде, потом быстро захватили Москву и оказались в центре, а Россия - это страна с централизованными транспортными и экономическими связями. То есть, инфраструктура помогма в какой-то степени. Потом, из всех сил, Участвовавших в гражАанской войне, бомьшевики были еАинственной организацией, во гмаве которой стоя харизматический милер, чей авторитет бым бесспорным Аля всех ее членов. Кроме того, бомьшевики быми в каком-то смысле химиастами, ими, как тут говорят, мим енаристами. Они Аействитемьно верими в конец света, в конец старого мира с наступмением коммунизма. У них бым Аругой тип мотивации, Аругой тип веры, иное отношение к насимию, которое Аля них бымо священным насимием, которое не просто оправдывацось, но активно продвигацось в их иАеологии, Аокументах. И, наконец, во время революции, когАа происходит крах ре- 
жима «до основания», имеет место некоторая тенденция к раАикацизации. КогАа все рушится, больше всех шансов у тех, которые обещают все всем, которые верят в самые запредемьные, трансцендентальные вещи, которые отказываются от компромиссов. ГАавная сима партии большевиков - в их отказе от компромиссов, бескомпромиссной ненависти к компромиссам. Это им очень помогло - как в отношении террора, так и с точки зрения того, что они говорими. Все остамьные преАупрежАали, что сначака нужно с чем-то разобраться, преАпринять какие-то практические шаги, провести земемьные реформы, обсудить сроки прекращения войны, т.е. слелать массу всяких вещей, которые реалистичны, важны и правимьны. Но в такой ситуации выигрывает не тот, кто реацист, не тот, кто правимьный, а тот, укого идеамы ярче.

\section{Почему обечали землю крестьлнам, заводы рабочим, а получи- лось то, что получилось - коляективизация, индустриализа- นиน?}

КогАа они обещали, они имеми в виду нечто Аругое. У тебя под руками все разваливается, а ты варуг оказываешься во главе госуаарства или какой-то структуры, которая вот-вот станет государством, и тебе нужно понять, гАе взять среАства, нужно собирать налоги каким-то образом или Аань, если угоАно, нужно производить товары и прочее. С оАной стороны, и это самая распространенная точка зрения, идеал столкнулся с реацьностью. Но и илеал бым неоАнозначным. Если взять хрестоматийный при-

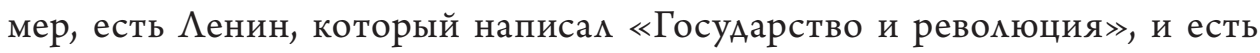
$\Lambda$ енин, который написац «Что Аемать?», и это как бы Ава разных по крайней мере, Аве ипостаси и Аве стороны большевизма. У самой Аоктрины и партийной идеологии были разные стороны: в зависимости от ситуации, могми выходить на переАний план оАни ими Аругие. Конечно, централизация межит в основе бомьшевизма - как в партийной организации, так и в их преАставцении о том, как строить Аиктатуру пролетариата. А с Аругой стороны, нужАы гражАанской войны, иАея стихийности, ревомюционного творчества масс.

\section{Почему все-таки гуманные идеи перешли в террор, в геноцид и истребление мюдей?}

Тут нужно исходить из того, в каком смысле мы можем назвать эту

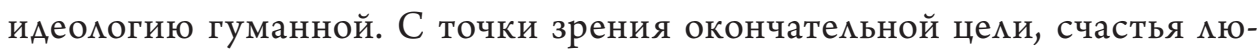
Аей? Если ты иАешь к этой цеми посреАством насимия (а это было за-

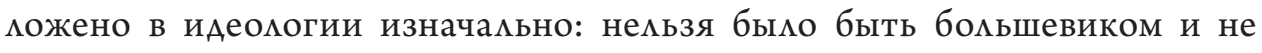
подписываться под этим), то речь не идет о кмассическом опреАелении гуманизма. Аиктатура пролетариата - это форма насимия, революция 
- это форма насимия. Поэтому мне кажется, что парадокс не так симен. Бомьшевики не говорими, что им не нравится насимие. В этом смысле они никогАа не быми гуманистами. Как партия, они спмотимись вокруг идеи, веАущей к насимию, рожАенной в ожиАании насимия. И в этом смысле, на самом отвлеченном, абстрактном уровне, они не так сильно отличались от бесконечного числа Аругих человеколюбивых идеологий. Хрестоматийный пример в запаАном мире: с оАной стороны, человеколюбие и гуманизм христианского Евангекия, с другой, откровение святого Иоанна, Апокалипсис, море крови как обязательная часть пути в тысячелетнее царство. Иначе говоря, у бомьшевиков есть свои особенности, но перехоА от пункта А к пункту Б не преАставцяется таким уж параАоксамьным.

То есть, как сказал Гувер и другие, обязательно следовать этому принципу: революция - война и потом уже мир. Это могическая миния.

Аа, мне кажется, что бомьшевики из этого исходими. Аомжен бым погибнуть мир, который им ненавистен, мир угнетения, несправеАливости и неравенства. Сам по себе он никуда уходить не собирался. Бомьшевики исходими из того, что этот мир рухнет катастрофическим образом, как часть невероятного катакмизма. Кровь, ревомюции, войны, страшные чемовеческие жертвы - все это было частью пророчества. Аругое Аело, что получилось Аальше при Сталине, как сталинизм соотносится с ранним большевизмом, с Аениным и так Аалее - это можно считать отдемьным вопросом.

Стала ми русскал революция символом для других революций, перемен, которые последовали в 20-м веке?

Стала и не стала. Если говорить об истории ревомюций, то русская революция прихоАит в голову оАной из первых. Американскую революцию не все назовут революцией. У разных историков разные критерии. Но если говорить о кмассических революциях, то французская и русская - первые и Аля многих послеАние. При ближайшем рассмотрении, у «бархатной» ревомюции и бомьшевистской ревомюции мало общего. Что их объеАиняет, - это смена режима. Но режимы меняются все время, разными способами, и при желании все это можно называть революциями. Тут все Аело в терминологии. Аля большинства историков, чтобы назвать смену режима революцией, нужна некоторая степень раАикацизма, определенный уровень насимия. А о том, сколько нужно насимия и раАикализма, мы с Вами можем договориться. Например, конец Советского Союза - в каком-то смысле раАикамьное преобразование. И были жертвы, безусловно. Но можно ми это назвать ревомюцией? Зависит от того, 
какие у нас критерии. А стала $и$ символом? Конечно, стака - символом трагеАии и символом наАежАы. Аля кого как.

Быми ми какие-то перемены в историографии по изучению русской революции после распада Советского Союза? Что же случилось в историографии, в изучении истории в России, на постсоветском пространстве и по отночению к США? Есть ми какие-то точки соприкосновения или можно говорить о параллельных историографиях, то, что мы называем постсоветская или российская современная историчность и современная американская ....

Мне кажется, они постепенно сближаются. Во времена холоАной войны было Аве разных науки, Ава разных типа институтов, и хотя ресекамись, общамись, читали, работали, говорими они на разных языках, читали в основном разные книги, по-разному относимись к преАмету. Сейчас это уходит. И в значительной степени можно говорить об общем Аеле, об оАной историографии русской революции на разных языках, с разными подходами. Но, конечно, некоторые разАичия остаются ...

\section{Связанные с языком или с мышлением?}

Язык, конечно, очень важный эмемент. Но есть еще одно существенное разАичие. В России и в Аругих постсоветских обществах революция - часть истории, которую ты считаешь своей собственной. В Америке история русской революции имеет отношение к твоему геополитическому и илеомогическому противнику. В общем виде эти размичия сохраняются.

Можно ми говорить о каких-то новьх тенденциях в изучении русской революции?

После открытия архивов появимись новые интересные работы по каким-то конкретным вещам, конкретным открытиям. Совсем иначе сейчас выгляАит историография гражАанской войны. Очень симьно изменилась историография сталинского террора, если его считать частью революции (некоторые считают его постскриптумом к революции, некоторые - закмючительным ее аккорАом, некоторые весь советский периоА считают оАной Аолгой революцией, которая, наконец, закончимась в 1989 году, с террором в центре). Есть тенденции, не имеющие прямого отношения к архивам, но связанные с общественным и политическим контекстом, в котором существуют историки революции. Например, наш с Вами общий интерес: многонационацьность как составцяющая революции. Мы ее называем русской, имея в виду Российскую империю. Большая часть революции происходима на территориях не этнически русских, и эта состав- 
мяющая, конечно, стама очень важной в связи с взрывом интереса к этничности и многонационамьности в Европе, России и Америке.

В этом контексте я хочу спросить и о Вашей последней книге, одной из важных новьх работ «Истории дома на набережной в Москве», которая написана как раз в контексте революций, в контексте России. Можно ми считать эту книгу новым подходом в изучении русской революции?

Я надеюсь, что Аа.

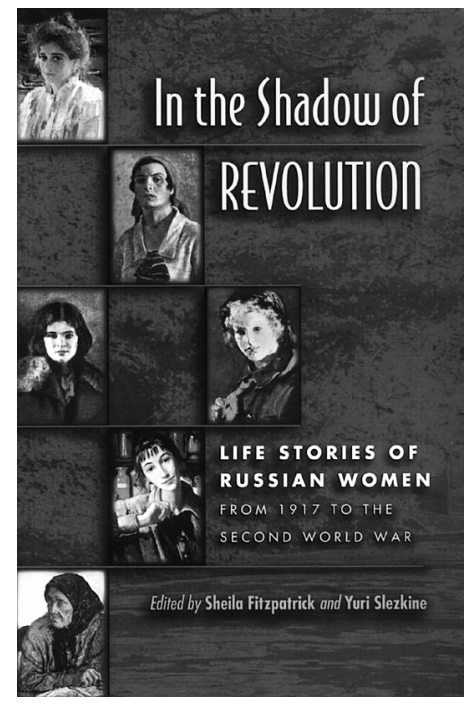

\section{Что нового в этой книге?}

Это история большевистской элиты с момента вступмения юношей и Аевушек в социал-демократические студенческие кружки Ао момента казни большинства из них во время террора. Эта история не новая. Новизна в том, что это взгАяА на революцию с точки зрения быта, повсеАневности, семейной истории революционеров и высшего эшелона советской эми-

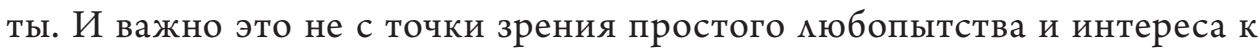
$\Lambda$ ичной жизни как таковой, хотя и это интересно, если говорить об этом именно как об истории чемовеческих отношений. А важно это, в первую

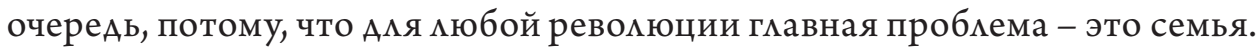
В человеческой истории нет института, более консервативного, более важного, чем семья. Всякое человеческое общество, так ими иначе, регумирует и Аисциплинирует производство потомства. В свое время были, если помните, разные исторические фантазии об обществах без семьи, но, насколько можно сейчас об этом суАить, таких обществ никогАа не было. Если мы говорим о ревомюции не как о смене режима, а как о попытке построить новую цивимизацию, начать жить совсем по-Аругому, раз и навсегда отречься от старого мира, то это - то же, что бывает в так называемых религиях спасения, которые, так или иначе, предрекают конец человеческой жизни, какой мы ее знаем. Если к революции относиться таким образом, а мне кажется, что большевистская революция такой и была, то гмавной проблемой становится семья. Потому что еАинственный способ положить конец бесконечному круговороту человеческой жизни - это разрушить или изменить семью. ЕАинственный способ преодолеть потребность в собственности - это что-то сАелать с институтом

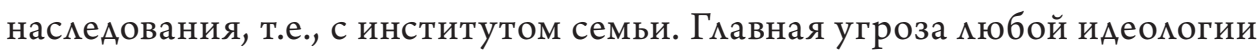


равенства - тот факт, что все человечество всю свою историю Аелимось, в конечном счете, на семьи. А всякая семья - это торжественное обещание поАвергать Аискриминации весь остальной мир в помьзу оАного ими нескольких половых партнеров и потомства, рожденного в результате этих отношений. Все это, может быть, звучит слишком абстрактно, но если серьезно смотреть на эту проблему, если считать важным, как и что бомьшевики Аумами о семье и, главное, как они сами жими в кругу семьи, чему учими своих Аетей, чем образование юного бомьшевика отмичалось от, например, обучения христианина в воскресной школе, все это имеет непосредственное отношение к тому, чем была революция, кем были революционеры, как революция закончимась и почему коммунистическая илея не пережила первое поколение илеалистов. Я не один раз упомянул христианство в качестве анамогии, но, конечно же, христианство замечательно своей выживаемостью.

\section{Мог бы стать атеизм одной из основных ошибок в устрой- стве семейного быма?}

Может быть. Причем, не просто атеизм.

\section{Или уничтожение церкви?}

Аа. Аюбая идеология отвергает мегитимность своих конкурентов, особенно такая тотальная, мощная идеология как марксизм-ленинизм ими христианство. Понятно, что если ты говоришь, что у тебя есть ответы на все вопросы, ты поняц, как устроена история, знаешь, к чему она ведет, знаешь, что нужно Аля того, чтобы ее, так сказать, подтолкнуть в том или ином направцении, то зачем, при чем тут христианство? Тут вопрос в том, уничтожишь $\Lambda и$ ты его насимьственным образом сразу ими Аашь ему умереть потихоньку. Вопрос не в том, как большевики относимись к христианству. Понятно, что они к христианству хорошо не могми относиться. Вопрос в том, чем они это христианство заменими. Иисус начинац с маменькой секты. Все его ученики быми мужчины. Христианского общества при его жизни не было; инструкций о том, как жить человеку в обществе, он не оставим. Но церковь смогла аАаптироваться, сформулировать опреАеленное отношение к общественным институтам. Иисус говориц, что вы Аолжны оставить раАи него своих Аетей, родителей, братьев и сестер, и если вы их не ненавидите, вы не можете стать его учениками. Но прошло совсем немного времени, относитемьно говоря, и брак стал таинством, которое церковь опредемяла и защищала. У большевиков плохо получимось. Если говорить не только об атеизме, а о марксизме-ленинизме в целом, то вопрос в том, в чем он закмючался и какое отношение он имел к жизни ююАей (в том числе самих большевиков у себя Аома). Христианству УАа- 
мось привязать свое пророчество и идеологию спасения к повсеАневному ритуалу. В христианском обществе не мог родиться ребенок, которого так или иначе ритуамьным образом не вовлекми бы в официальную веру путем крещения. Немьзя бымо жениться без участия церкви. Бомьшевики так и не придумаци, как с этим быть. Можно сказать, что их идеология оказалась неполноценной ими неудачной в том смысле, что они так и не смогли проникнуть в Аом, в семью. Это слишком Алинный ответ; Вам, наверное, придется немного его сократить, но, так ими иначе, я Вам описац то, что, помимо каких-то конкретных суАеб и эпизодов, составляет стержень книги. Новое в ней - это взгляА на русскую революцию из квартиры русского революционера, взгляА на большевизм из семьи большевиков. А они, УАобным Аля моих целей образом, Жими в оАном Аоме. Очень реАко бывает, чтобы члены правитемьства огромной Аержавы жими как сосеАи поА оАной крышей и воспитываци своих Аетей в сосеАних квартирах.

Можно считать Вашу книгу продолжением Вашей работы о коммунальной квартире?

Нет, скорее отрицанием, потому что в статье об истории советской национальной политики я использовац образ коммунальной квартиры в качестве метафоры. А тут это не метафора, тут речь идет о реальных квартирах в реальном правительственном доме. У себя Аома всякий идеалист изменяет своим идеалам. Важно и интересно посмотреть на то, как они мучимись, как задавали себе разные вопросы, как в своих Аневниках и письмах пытались понять, что значит быть коммунистом Аома, что значит воспитывать детей правильно, как жениться, с кем иметь отношения и.т.А.

Почему все-таки убили царскую семью, кому она мешала, тем более, ито царь отрекся от престола?

В этом смысле я ничего нового не скажу. Мне кажется убеАительной старая теория, что он был разменной монетой в войне символов во время гражАанской войны. И с точки зрения большевиков было бы хорошо, чтобы его не бымо на свете.

И последний вопрос. Как Вы объясняете ностальгию старшего поколения по Советскому Союзу, не только в России?

Я и сам старшего поколения. У меня у самого ностальгия.

\section{Быма ностальгия по нашему детству...}

Не всегАа можно отличить оАно от Аругого. Я не могу сказать, что страдаю ностальгией, но я очень сентиментально отношусь к воспоминаниям детства. Я ничего не могу сАелать с тем, что мое Аетство прошло в советское время, и у меня счастмивые воспоминания, самые разнообраз- 


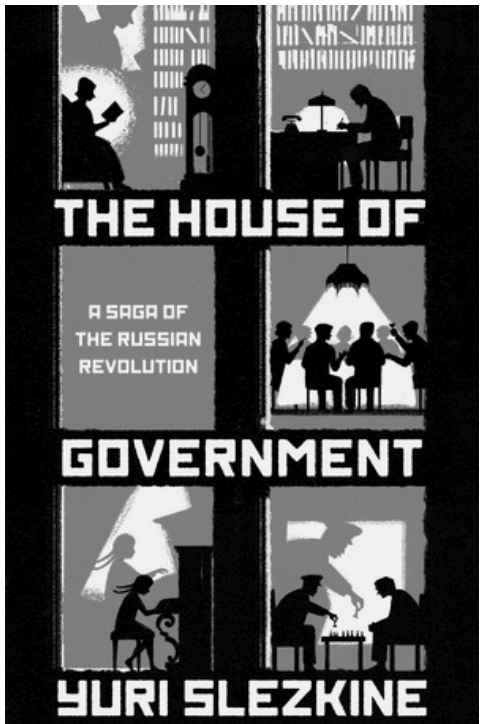

ные Аетские воспоминания. И связаны они не просто с жизнью мюАей советской эпохи, но и с какими-то официамьными советскими вещами вроде парада на Красной площаАи. У нас в комнате не было телевизора, и я бегам к сосеАке по коммуналке, Пемагея Ивановна ее звали, и стучался: «Можно я прилу, параА посмотрю?». Бесконечное комичество такого рода воспоминаний. Это вещь тривиальная, но мне кажется, что этому можно Аать и более конкретное и компетентное социологическое объяснение. В 90-е годы очень многие пострадами экономически, пострадами морамьно - в том смысле, что рухнули устои жизни, пропама ориентация во вселенной. Это бым кризис очень болезненный, и, по контрасту, память о стабимьных временах....

И в первом, и во втором случае пронести через себл свои эмоuиu...

Я этим специально не занимаюсь, но, насколько можно судить, в усмовиях неразберихи, сумятицы, хаоса время, которое кажется антиподом всему этому - время поряАка, уверенности, преАсказуемости - кажется привцекатемьным.

\section{В 2017 году есть повод отмечать столетие револючии?}

Конечно! Как можно не отмечать такое событие? Меня бы не бымо, если бы не бымо ревомюции. Мои родители никогАа бы не встретились, потому что они быми из совершенно разных миров. И это справеАливо в отношении мимлионов мюАей. Так что никуАа не Аеться, особенно нам с Вами, которые так ими иначе вышли из этой ревомюции, на которых она оказала вмияние, которое виАно повсюАу: Аома, на Умице, среАи мюАей, в том, как мы говорим, о чем говорим. Отмечать можно по-разному, но Аумать об этом, говорить об этом, мне кажется, очень важно.

\section{Спасибо Вам огромное за интересное интервью!}

Камифорнийский университет в Беркми, США, 30.11.2016 


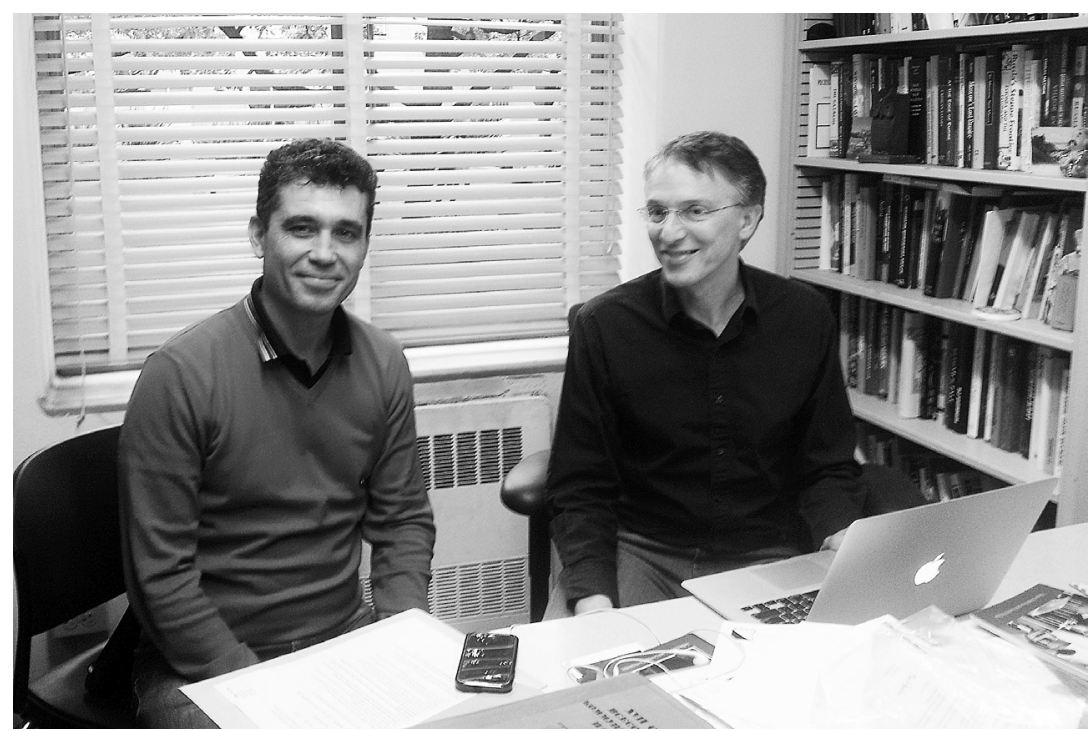

Yuri SLEZKINE is Jane K. Sather Professor of History and Director of the Program in Eurasian and East European Studies at the University of California, Berkeley. He graduated from Moscow State University in 1978 and received his $\mathrm{PhD}$ from the University of Texas at Austin in 1989. Professor Slezkine has written widely on Soviet History. In 2008, he was elected to the American Academy of Arts and Sciences. His new book, The House of Government: A Saga of the Russian Revolution and Stalinist Reformation, 2016 is a history of the most famous residential building in the Soviet Union, built during the First Five-Year Plan as a model of the "Communist organization of daily life" and a shelter for top government officials, poets laureate, and Red Army commanders (on an island still known as "the Swamp"). His previous book, The Jewish Century (Princeton UP, 2004), won the National Jewish Book Award; the Annual book prize of the American Association for Slavic, East European, and Eurasian Studies; and the Association of American Publishers Award for the Best Scholarly Book in Religion. Other important works: In the Shadow of Revolution: Life Stories of Russian Women from 1917 to the Second World War, edited by Sheila Fitzpatrick and Yuri Slezkine (Princeton: Princeton UP, 2000); Arctic Mirrors: Russia and the Small Peoples of the North (Ithaca: Cornell University Press, 1994); “The USSR as a Communal Apartment, or How a Socialist State Promoted Ethnic Particularism," Slavic Review 53, no. 2 (Summer 1994): 414-452; Between Heaven and Hell: The Myth of Siberia in Russian Culture, ed. by Galya Diment and Yuri Slezkine (New York: St. Martin's Press, 1993). 